\title{
Isolation and Culture of a Thermophilic Fungus, Melanocarpus albomyces, and Factors Influencing the Production and Activity of Xylanase
}

\author{
By RAMESH MAHESHWARI* AND P. T. KAMALAM \\ Department of Biochemistry, Indian Institute of Science, Bangalore 560 012, India
}

(Received 15 April 1985; revised 22 June 1985)

\begin{abstract}
An uncommon thermophilic fungus, Melanocarpus albomyces, was isolated from soil and compost by incubating samples in a glucose/sorbose/asparagine liquid medium, followed by enrichment culture in medium containing sugarcane bagasse as carbon source. The culture filtrate protein of the fungus grown in the presence of bagasse or xylose hydrolysed xylan and some other polysaccharides but cellulose was not hydrolysed. High extracellular xylanase (EC $3.2 .1 .8)$ activity was produced by cultures grown on xylose or hemicellulosic materials. The enzyme was induced in glucose-grown washed mycelia in response to addition of xylose or xylan but not by alkyl or aryl $\beta$-D-xylosides. Cultures produced higher enzyme yields in shaken flasks than in a fermenter. Gel-filtration chromatography of culture filtrate protein showed the presence of two isoenzymes of xylanase, whose relative proportions varied with the carbon source used for growth. The extent of hydrolysis of heteroxylans or the hemicellulosic fraction of bagasse by culture filtrate protein preparations was greater when the cultures had been grown on bagasse rather than xylose as the inducing substrate. The activity of xylanase preparations was increased when an exogenous $\beta$-glucosidase was added.
\end{abstract}

\section{INTRODUCTION}

There is increasing interest in fungi which can produce high levels of enzymes capable of degrading plant cell-wall polysaccharides. Such enzymes are useful as specific tools for elucidating the structure of plant cell walls, and are also required for evolving biodegradative methods for the conversion of biomaterials containing cellulose and hemicellulose into monosaccharides from which single-cell protein, single-cell oil or ethanol could be produced (Flickinger, 1980; Fall et al., 1984). During a search for thermophilic fungi with biodegradative capability, an uncommon fungus, Melanocarpus albomyces (Cooney \& Emerson) von Arx, was isolated for the first time from India. In this paper we report the isolation and culture of this fungus, and also describe the induction of xylanase in cultures and the conditions which influence its production and activity. The fungus can rapidly produce high levels of extracellular xylanase in culture medium incorporating bagasse, a surplus by-product of the sugar-milling industry, and it is one of the most active producers of xylanase discovered so far.

\section{METHODS}

Soil collection. Samples of soil from forests and compost were collected from different places in India. These were brought to the laboratory in small polyethylene bags and stored at $4{ }^{\circ} \mathrm{C}$ for several months before use.

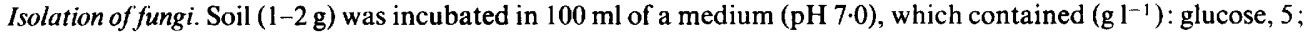
L-sorbose, $10 ; \mathrm{L}$-asparagine, $\mathrm{I} ; \mathrm{K}_{2} \mathrm{HPO}_{4}, 1 ; \mathrm{MgSO}_{4} .7 \mathrm{H}_{2} \mathrm{O}, 0.5 ;$ streptomycin sulphate, 0.03 and rose bengal, 0.06 . After $3 \mathrm{~d}$ growth at $50^{\circ} \mathrm{C}$ on a gyratory shaker ( 240 r.p.m.), the fungal growth was transferred to fresh medium of the above composition except that the sugars were replaced with $1 \%(\mathrm{w} / \mathrm{v})$ sugarcane bagasse, which served as a source of plant cell-wall polysaccharides, containing about $36 \%$ cellulose and $26 \%$ hemicellulose (Paturau, 1982). The fungal growth was subcultured after $4 \mathrm{~d}$. Finally, after $7 \mathrm{~d}$, individual fungi were isolated at $50{ }^{\circ} \mathrm{C}$ by plating a suitably diluted sample of the culture on YpSs agar (Cooney \& Emerson, 1964) containing streptomycin sulphate and rose bengal at the concentrations mentioned above.

0001-2634 C 1985 SGM 
Culture of Melanocarpus albomyces. Strain IIS 68 (see Results) was used for all the experiments unless otherwise stated. A semi-synthetic medium was used, containing ( $\left.\mathrm{g} \mathrm{l}^{-1}\right)$ : glucose, 20 ; urea, $0.5 ; \mathrm{KH}_{2} \mathrm{PO}_{4}, 0.6 ; \mathrm{K}_{2} \mathrm{HPO}_{4}, 0 \cdot 4$; $\mathrm{MgSO}_{4} \cdot 7 \mathrm{H}_{2} \mathrm{O}, 0 \cdot 5$ and yeast extract, 1 . The $\mathrm{pH}$ of the medium before autoclaving was 6.0. A suspension of mycelia scraped from agar cultures stored at room temperature for 4-6 months was added to the sterile medium. The fungus was grown in $150 \mathrm{ml}$ medium in $500 \mathrm{ml}$ Erlenmeyer flasks on a gyratory shaker at $40^{\circ} \mathrm{C}$, unless stated otherwise. Peptone $(0.5 \%, \mathrm{w} / \mathrm{v})$ was added to the medium when bagasse was used as inducing substrate as it tended to increase xylanase yield by about $1 \cdot 5$-fold.

Xylanase (EC 3.2.1.8) production. Xylose or bagasse $(1.5 \%, \mathrm{w} / \mathrm{v})$ was used as inducing substrate. For studies of growth and enzyme production, cultures were initiated by adding a $5 \%(\mathrm{v} / \mathrm{v})$ mycelium inoculum from a $48 \mathrm{~h}$ culture grown in glucose/urea medium as above.

Xylanase production was also studied in a Microferm fermenter (New Brunswick), using 31 medium. A $5 \%$ $(\mathrm{v} / \mathrm{v})$ mycelial inoculum was added and the starting $\mathrm{pH}$ of the culture was adjusted to 6.0 by addition of $4 \mathrm{M}-\mathrm{HCl}$.

Enzyme assays. To determine cellulase activity, $1 \mathrm{ml}$ reaction mixture containing approximately $50 \mathrm{mg}$ $(1 \times 6 \mathrm{~cm}$ strip) Whatman no. 1 filter paper was incubated with culture filtrate in sodium/potassium phosphate buffer (pH $6.0,50 \mathrm{mM}$ ) for $30 \mathrm{~min}$ at $50^{\circ} \mathrm{C}$. The glucose released was quantified by the glucose oxidase-peroxidase method (McComb \& Yushok, 1957). Cellulase activity on carboxymethylcellulose (Na salt) was determined using $0.5 \mathrm{ml} 1 \%(\mathrm{w} / \mathrm{v})$ substrate. The reducing end-groups liberated were measured by the Nelson-Somogyi method (Somogyi, 1952).

Xylanase activity was determined with larchwood xylan as substrate. A $2 \mathrm{ml}$ reaction mixture containing $0 \cdot 2 \mathrm{ml}$ $1 \%(w / v)$ xylan and a sample of 100 -fold diluted culture filtrate was incubated in sodium/potassium phosphate buffer (pH 6.0, $50 \mathrm{~mm}$ ) for $30 \mathrm{~min}$ at $50^{\circ} \mathrm{C}$. The reducing end-groups liberated were measured as above.

$\beta$-Glucosidase and $\beta$-xylosidase activity in culture solutions were assayed using $p$-nitrophenyl $\beta$-Dglucopyranoside and $p$-nitrophenyl $\beta$-D-xylopyranoside, respectively. The reaction mixture $(1 \mathrm{ml})$ contained culture filtrate and $0.5 \mathrm{ml} 1 \mathrm{~mm}$ substrate in phosphate buffer ( $\mathrm{pH} 6.0,50 \mathrm{~mm})$, and was incubated for $30 \mathrm{~min}$ at $50{ }^{\circ} \mathrm{C}$. Reaction was stopped by adding $2 \mathrm{ml} 5 \%(\mathrm{w} / \mathrm{v}) \mathrm{Na}_{2} \mathrm{CO}_{3}$ and the absorbance of the solution was measured at $400 \mathrm{~nm}$. $\beta$-Xylosidase activity was also tested with methyl $\beta$-D-xyloside as substrate, measuring the formation of xylose by the Nelson-Somogyi method.

One unit of enzyme activity on a polysaccharide substrate was defined as $1 \mu$ mol reducing end-groups released $\min ^{-1}$ under the above assay conditions. One unit of $\beta$-glucosidase activity was defined as that amount of enzyme which produced $1 \mu \mathrm{mol} p$-nitrophenol $\mathrm{min}^{-1}$ under the assay conditions.

Polysaccharide degradation. The activity of culture filtrate protein towards polysaccharides was determined by measuring the generation of reducing sugars, and is expressed as percentage saccharification, calculated as [reducing sugar $(\mathrm{mg}) \times 0.9 \times 100] /[$ initial substrate $(\mathrm{mg})$ ]. (This equation is for hexoses, but is a close enough approximation for pentoses.) The protein preparation was obtained by precipitation of culture filtrates with $80 \%$ saturated ammonium sulphate, and was desalted before use, as described below.

Column chromatography of xylanase. To culture filtrates (31) from 4-d-old cultures grown on xylose or bagasse, ammonium sulphate was added to $80 \%$ saturation with constant stirring. The preparation was allowed to stand overnight at $4{ }^{\circ} \mathrm{C}$, and the precipitated material was collected by filtering through a Celite bed. When suspended in distilled water it gave a dark brown solution containing about $80 \%$ of the original xylanase activity. This solution was treated with ammonium sulphate at $40 \%$ saturation. The resulting precipitate was dissolved in water and the dark solution was desalted in batches by chromatography on a Sephadex G-25 column $(106 \times 2.5 \mathrm{~cm})$. The active fractions were combined; they contained about $60 \%$ of the original xylanase activity. The solution was lyophilized, and the dry powder was dissolved in ammonium acetate buffer ( $\mathrm{pH} 6.2,75 \mathrm{mM})$. The enzyme solution was applied to a column $(14 \times 2.7 \mathrm{~cm})$ of DEAE-Sephadex A-50 $(\mathrm{pH} \mathrm{6.2)}$ and eluted with the same buffer. The pigments were adsorbed by the ion-exchanger, whereas the enzyme was eluted in the buffer wash and was almost free of colour. The appropriate fractions were pooled and lyophilized. A portion $(21 \mathrm{mg})$ was dissolved in water and subjected to gel-filtration chromatography on a Sephadex G-75 column $(100 \times 2 \mathrm{~cm})$ eluted with water at $10 \mathrm{ml} \mathrm{h}^{-1} ; 3 \mathrm{ml}$ fractions were collected. Protein was monitored by absorbance at $280 \mathrm{~nm}$.

Biochemicals. These were mostly purchased from Sigma. Araban and galactan were from Koch-Light. Gelfiltration and other chromatography media were from Pharmacia. Cellulase and $\beta$-glucosidase were purified from culture filtrates of Sporotrichum thermophile by K. M. Bhat in this laboratory. Sugarcane bagasse was obtained from Mandya Sugar Mills, Karnataka, India. It was air-dried, milled and sieved through a 60 mesh screen $(250 \mu \mathrm{m})$ before use.

\section{RESULTS}

\section{Identification of the fungus}

Colonies of $M$. albomyces were distinguishable from other thermophilic fungi present (Penicillium duponti, Thermomyces lanuginosus, Malbranchea pulchella var. sulfurea) on YpSs agar 
isolation medium by their white mycelia and lack of sporogenous hyphae. Three colonies of $\boldsymbol{M}$. albomyces were obtained: one from soil (IIS 66) and two from compost (IIS 67 and IIS 68). The colonies were composed of two distinct hyphal types: thin, thread-like aerial hyphae and prostrate hyphae constricted at the septa to form chains of oval cells with thickened walls (arthroconidia).

When grown singly on $\mathrm{YpSs}$ agar at $40{ }^{\circ} \mathrm{C}$, the isolates produced ascocarp-like structures after about 3-4 weeks, but these contained no spores. When the three isolates were grown together on YpSs agar (Fig. 1 a), dark lines of fruiting bodies appeared in about 10-14 d where the edges of the mycelium of isolate IIS 67 crossed those of isolates IIS 66 or IIS 68, showing that the fungus was heterothallic. Fruiting bodies did not form between isolates IIS 66 and IIS 68, which thus belong to the same mating type, whereas IIS 67 is of the opposite mating type. Figs $1(c)$ and $1(d)$ show stages in the formation of an ascocarp. The mature ascocarp was spherical and dark brown. It lacked an ostiole (Fig. 1e). Each ascocarp contained numerous asci, which oozed out when the ascocarp was ruptured by mechanical pressure on the cover slip (Fig. ( $1 f$ ). The young ascus was kidney-shaped and contained eight ascospores, arranged as two tetrads (Fig. $1 g, h$ ). The mature ascospores were oval and dark brown (Fig. 1 $i$ ). The morphology of our isolates resembled the description given by Cooney \& Emerson (1964) for the thermophilic fungus Myriococcum albomyces, but with the difference that the ascocarps they observed generally contained fewer asci or were completely sterile. von Arx (1981) has reassigned Myriococcum albomyces as Melanocarpus albomyces.

\section{Growth and physiological characteristics}

Nitrogen source. Strain IIS 68 was cultured in media containing $\left(\mathrm{NH}_{4}\right)_{2} \mathrm{SO}_{4},\left(\mathrm{NH}_{4}\right)_{2} \mathrm{HPO}_{4}$, $\mathrm{NH}_{4} \mathrm{H}_{2} \mathrm{PO}_{4}, \mathrm{NaNO}_{3}$, L-asparagine or urea at equivalent nitrogen concentration $(0.023 \%)$, with $2 \%(\mathrm{w} / \mathrm{v})$ glucose as carbon source. Measurement of mycelial yield (dry wt per $50 \mathrm{ml}$ ) after $4 \mathrm{~d}$, when growth had more or less ceased, showed that the ammonium compounds produced poor growth $(5-12 \mathrm{mg}$ ) and the $\mathrm{pH}$ of the culture medium dropped to approximately $4 \cdot 2$. Better growth occurred in medium containing L-asparagine $(112 \mathrm{mg})$, urea $(148 \mathrm{mg})$ or $\mathrm{NaNO}_{3}$ $(164 \mathrm{mg})$. The $\mathrm{pH}$ of these media either did not change significantly during growth (asparagine and urea), or it rose to $7.5\left(\mathrm{NaNO}_{3}\right)$. These results suggested that the fungus did not tolerate acidic conditions which presumably resulted from the absorption of $\mathrm{NH}_{4}^{+}$and counter-transport of $\mathrm{H}^{+}$, as has been shown for Penicillium cyclopium (Roos \& Luckner, 1984). Urea was chosen as the nitrogen source for subsequent culture as it produced satisfactory yields and the mycelia grew as small pellets (approximately $1-3 \mathrm{~mm}$ in diameter).

Temperature. In liquid shaken cultures at 30,40 and $50^{\circ} \mathrm{C}$, the rate of growth (measured as dry weight per $20 \mathrm{ml}$ of culture) was fastest at $50^{\circ} \mathrm{C}$, reaching a maximum $(149 \mathrm{mg}$ ) on day 2 , after which the dry weight declined rapidly, being $90 \mathrm{mg}$ on day 4 . At $40^{\circ} \mathrm{C}$, the maximal mycelial yield was $126 \mathrm{mg}$, on day 2 , after which the dry weight again declined. At $30^{\circ} \mathrm{C}$, the yield was maximal $(176 \mathrm{mg})$ on day 3 and remained the same on day 4 when the experiment was terminated. The fact that growth rate was maximal at $50^{\circ} \mathrm{C}$, confirmed the thermophilic character of the isolate.

\section{Hemicellulose-degrading activity}

As the fungus was isolated after enrichment culture in medium containing bagasse, it was assumed that it could degrade some isolated polysaccharide constituents of plant cell walls. The fungus was cultured in a bagasse/urea medium for $4 \mathrm{~d}$, and the culture filtrate was tested for its ability to hydrolyse polysaccharides (Table 1). Of the polysaccharides tested, only starch, lichenan and xylan were appreciably degraded. The inability of the fungus to degrade cellulose was confirmed by growing it in a medium containing filter paper supplemented with $0.5 \%(\mathrm{w} / \mathrm{v})$ peptone. Microscopic examination at intervals showed that although the cellulose fibres were fragmented and shorter fibres were generated within $24 \mathrm{~h}$, these were not solubilized till day 6 . The final cellulase activity of culture filtrates was very low: less than $0.01 \mu$ mol glucose $\mathrm{min}^{-1} \mathrm{ml}^{-1}$ was liberated. 

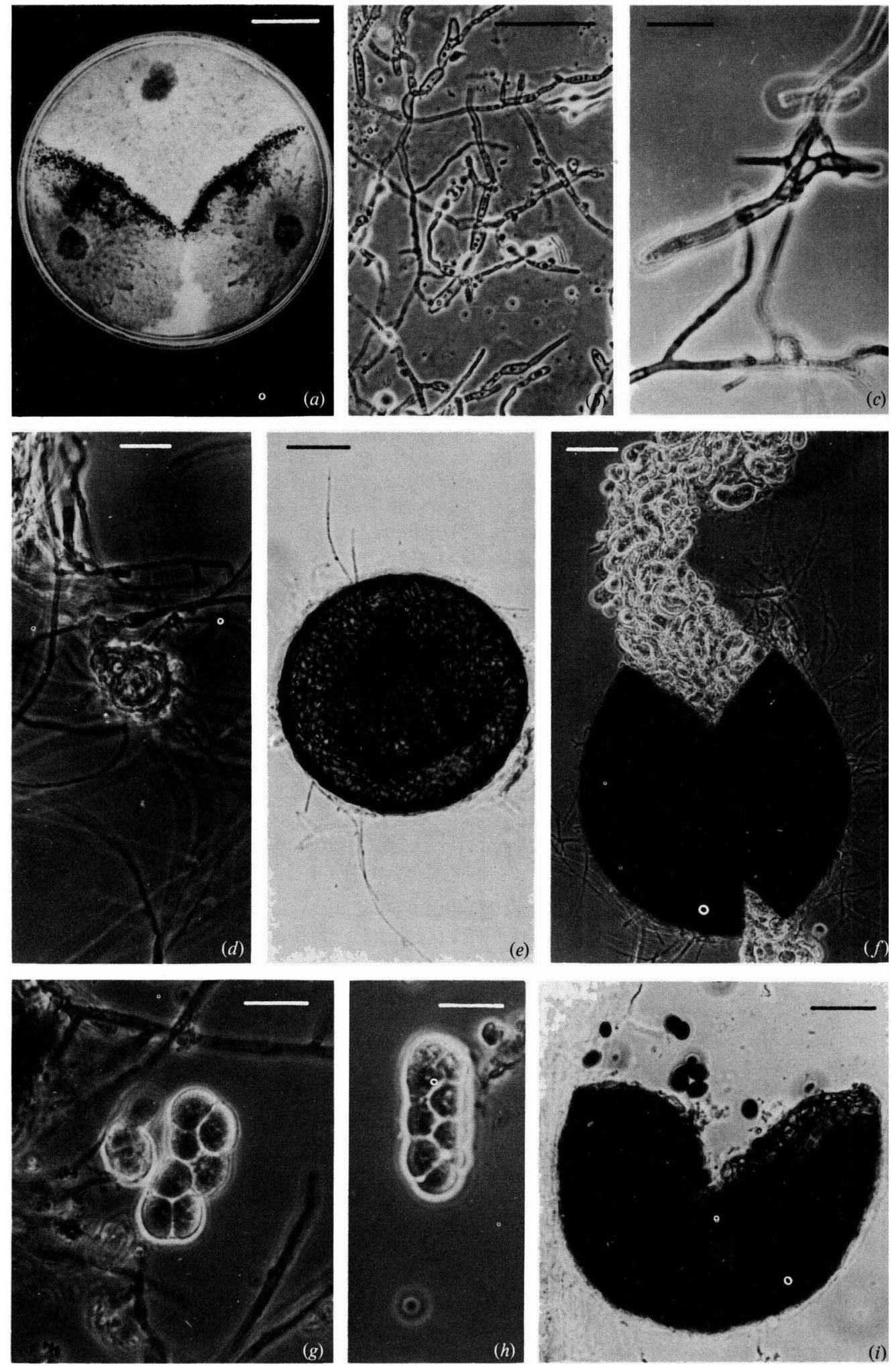
Table 1. Activity of $M$. albomyces culture filtrates on some polysaccharides

\begin{tabular}{|c|c|c|c|}
\hline Substrate & $\begin{array}{l}\text { Predominant } \\
\text { residue }\end{array}$ & $\begin{array}{l}\text { Backbone } \\
\text { linkage(s) }\end{array}$ & $\begin{array}{c}\text { Percentage } \\
\text { saccharification }\end{array}$ \\
\hline Araban & Arabinose & $\alpha-1,5 ; \alpha-1,3$ & 6.4 \\
\hline Cellulose & Glucose & $\beta-1,4$ & $2 \cdot 8$ \\
\hline Dextran & Glucose & $\alpha-1,6$ & $7 \cdot 7$ \\
\hline Galactan & Galactose & $\beta-1,4 ; \beta-1,3$ & $1 \cdot 0$ \\
\hline Lichenan & Glucose & $\beta-1,3 ; \beta-1,4$ & $37 \cdot 4$ \\
\hline Mannan & Mannose & $\beta-1,4$ & $1 \cdot 0$ \\
\hline $\begin{array}{l}\text { Polygalacturonic } \\
\text { acid }\end{array}$ & $\begin{array}{l}\text { Galacturonic } \\
\text { acid }\end{array}$ & $\alpha-1,4$ & 0 \\
\hline Starch & Glucose & $\alpha-1,4$ & $46 \cdot 0$ \\
\hline Xylan & Xylose & $\beta-1,4$ & $29 \cdot 0$ \\
\hline
\end{tabular}

\section{Effect of carbon sources on production of xylanase}

As the culture filtrates had high activity towards xylan, which is the dominant hemicellulose present in most types of fibrous plant material, attention was focused on xylanase. The production of extracellular xylanase by $M$. albomyces cultured in the presence of some mono-, diand polysaccharides was studied to determine whether the enzyme was synthesized constitutively or produced only in response to certain carbon sources. The enzyme was produced in significant amounts only in media containing xylose or xylan (Table 2). Unlike results obtained with some other fungi (Dekker \& Richards, 1976; Mishra et al., 1984), cellulose induced very low levels of xylanase. Our results suggested that xylanase in this fungus is induced only by xylosic material; the induction of enzyme by araban was taken to be due to the presence of xylose residues in this material (Dekker \& Richards, 1976). The culture filtrates which were active on xylan were tested for $\beta$-xylosidase activity, but none was detected.

The inducibility of xylanase in $M$. albomyces was further tested by studying the response of cultures to the delayed addition of xylose or hemicellulosic material (bagasse). Cultures initiated in medium with glucose as the carbon source showed low levels $\left(1.0-0.5\right.$ units $\left.\mathrm{ml}^{-1}\right)$ of xylanase (day 1 or day 2 ) or none at all (day 3 ). However, $24 \mathrm{~h}$ after the addition of $2 \%(\mathrm{w} / \mathrm{v})$ xylose to a separate set of flasks on day 2 , the cultures had an enzyme level of 7 units $\mathrm{ml}^{-1}$. A greater induction response ( 12 units $\mathrm{ml}^{-1}$ ) occurred in the same time when $2 \%(\mathrm{w} / \mathrm{v})$ bagasse was added. These results confirmed the inducibility of xylanase in the fungus.

\section{Xylanase induction in washed mycelia}

The time-course and the amount of induced enzyme formed suggested that this system might be useful for the study of the induction phenomenon using washed mycelia. Mycelia from 2-dold cultures grown in glucose/urea medium were collected by filtration, washed with distilled water and the effect of different constituents of the growth medium on xylanase induction by xylose $(0.5 \%, \mathrm{w} / \mathrm{v})$ was tested. Extracellular xylanase was induced by xylose in mycelia incubated with unsupplemented buffer components $\left(0.4\right.$ units $\mathrm{ml}^{-1}$ after $4 \mathrm{~h}$ at $\left.40^{\circ} \mathrm{C}\right)$, and the amount produced increased with cumulative additions of urea $\left(0.6\right.$ units $\left.\mathrm{ml}^{-1}\right), \mathrm{MgSO}_{4}(0.7$ units

Fig. 1. Melanocarpus albomyces. (a) An agar plate inoculated with three isolates, IIS 67, 68 and 66, at approximately 12, 4 and 8 o'clock positions, respectively. Dark lines of fruiting bodies are visible between IIS 67 and 66 and between IIS 67 and 68. Bar, $5 \mathrm{~mm}$. (b) Prostrate mycelia. Bar, $100 \mu \mathrm{m}$. (c) An early stage in development of an ascocarp (presumably plasmogamy). Bar, $20 \mu \mathrm{m}$. (d) Protoperithecium-like structure. Bar, $20 \mu \mathrm{m}$. (e) Surface view of ascocarp. Bar, $50 \mu \mathrm{m}$. $(f)$ Ruptured ascocarp liberating numerous asci. Bar, $50 \mu \mathrm{m}$. $(g)$ A young ascus with clumped ascospores. Bar, $50 \mu \mathrm{m} .(h)$ An ascus showing eight ascospores. Bar, $20 \mu \mathrm{m}$. (i) A cracked mature ascocarp and dark oval ascospores. Bar, $50 \mu \mathrm{m}$. 
Table 2. Production of xylanase by $M$. albomyces in media containing different carbon sources

Carbohydrates were tested at $0 \cdot 5 \%(\mathrm{w} / \mathrm{v})$. Enzyme activity was measured after $5 \mathrm{~d}$ growth. The data for the monosaccharides, the disaccharides and xylan are means of four experiments; the other data are means of two experiments.

$\begin{array}{lc}\text { Carbon source } & \begin{array}{c}\text { Xylanase } \\ \text { (units } \mathrm{ml}^{-1} \text { ) }\end{array} \\ \begin{array}{l}\text { Monosaccharides } \\ \text { Glucose }\end{array} & 0 \cdot 5 \\ \text { Xylose } & 10 \cdot 7 \\ \text { Disaccharides } & \\ \text { Cellobiose } & 0 \cdot 2 \\ \text { Lactose } & 0 \cdot 8 \\ \text { Polysaccharides } & \\ \text { Araban } & 4 \cdot 0 \\ \text { Cellulose (Sigmacell) } & 1 \cdot 2 \\ \text { Chitin } & 0 \cdot 7 \\ \text { Galactan } & 0 \cdot 5 \\ \text { Inulin } & 0.8 \\ \text { Lichenan } & 0 \cdot 4 \\ \text { Pectin } & 0.5 \\ \text { Starch } & 0.5 \\ \text { Xylan } & 12 \cdot 0\end{array}$

$\left.\mathrm{ml}^{-1}\right)$ and yeast extract + peptone $\left(0.9\right.$ units $\left.\mathrm{ml}^{-1}\right)$. Therefore, all the above components were included in the induction medium. When, in a separate experiment, washed mycelia grown for $2 \mathrm{~d}$ on the glucose/urea medium were resuspended in this medium with glucose replaced by xylose or xylan (each $0.5 \%, \mathrm{w} / \mathrm{v}$ ), and incubated for $4 \mathrm{~h}$ at $40{ }^{\circ} \mathrm{C}, 0.6$ and 1 unit xylanase $\mathrm{ml}^{-1}$, respectively, was induced. Methyl $\beta$-D-xyloside and $p$-nitrophenyl $\beta$-D-xyloside were ineffective as inducers, as were cellobiose and carboxymethylcellulose (all at $0.5 \%, \mathrm{w} / \mathrm{v}$ ). The level of induced enzyme produced in short-term incubations was equal to or higher than that produced by some micro-organisms during long-term culture on xylan or other substrates (Baker et al., 1977; Biely et al., 1980; Zalewska-Sobczak \& Urbanek, 1981; Yoshioka et al., 1981).

\section{Culture conditions for xylanase production}

Temperature. A study of xylanase production at 30,40 and $50{ }^{\circ} \mathrm{C}$ showed that maximal stable enzyme activity was obtained at $40^{\circ} \mathrm{C}$ (Fig. 2). This temperature was therefore used for all studies on xylanase production.

Carbon and nitrogen concentration. To determine the optimal concentrations of carbon (inducer) and nitrogen, xylose was tested at $0.5,1 \cdot 0,1 \cdot 5$ and $2 \cdot 0 \%(\mathrm{w} / \mathrm{v})$ with urea at $0.05,0 \cdot 1,0 \cdot 2$ and $0.4 \%(\mathrm{w} / \mathrm{v})$ in all possible combinations. An activity of $>8$ units $\mathrm{ml}^{-1}$ was produced in all cases but a combination of $1.5 \%(\mathrm{w} / \mathrm{v})$ xylose and $0.2 \%(\mathrm{w} / \mathrm{v})$ urea produced the maximal yield of xylanase $\left(22 \cdot 5\right.$ units $\mathrm{ml}^{-1}$ in $\left.4 \mathrm{~d}\right)$.

Time. The increase in xylanase activity in xylose medium paralleled growth, and activity was maximal on day 3 or day 4 (Fig. 3). With bagasse as inducer, the maximal xylanase activity was again obtained on day 3 or day 4 . With either xylose or bagasse as inducer the $\mathrm{pH}$ of the culture medium rose to nearly 8.8 by the end of growth.

Inducing substrates. The yield of xylanase with bagasse or xylose as the inducing substrate was generally similar, particularly if bagasse was used in combination with $0.5 \%(\mathrm{w} / \mathrm{v})$ peptone. This was so despite the fact that, judged visually, the mycelial growth with bagasse was only about one-tenth of that in xylose medium. The average xylanase yield from 7-10 experiments in shake flask cultures was 15 units $\mathrm{ml}^{-1}$ with $1.5 \%(\mathrm{w} / \mathrm{v})$ bagasse or xylose.

With $1.5 \%(\mathrm{w} / \mathrm{v})$ bagasse, the effect of supplementary addition of a soluble carbohydrate $(0.5 \%, \mathrm{w} / \mathrm{v})$ on xylanase yield was studied. Addition of glucose, starch or xylose increased enzyme production by up to $1 \cdot 3$-fold over the bagasse control $\left(11.8\right.$ units $\left.\mathrm{ml}^{-1}\right)$, and addition of 


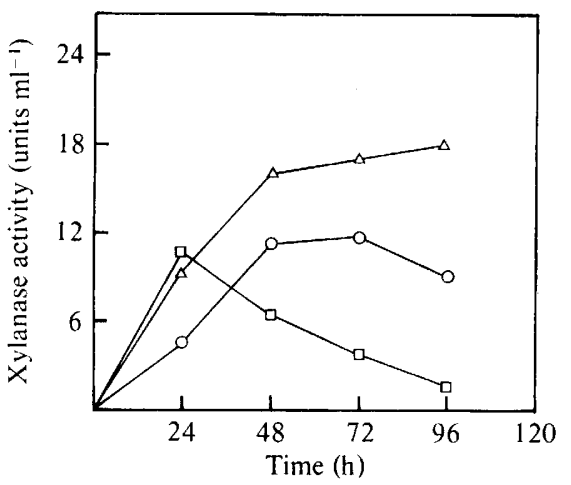

Fig. 2

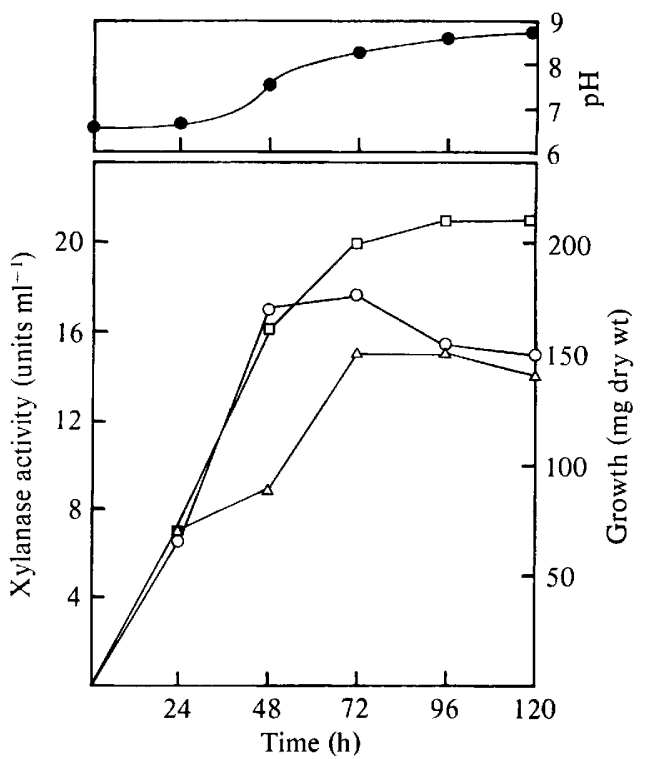

Fig. 3

Fig. 2. Extracellular xylanase activity in shake flask cultures incubated at $30^{\circ} \mathrm{C}(\mathrm{O}), 40^{\circ} \mathrm{C}(\triangle)$ and $50^{\circ} \mathrm{C}(\square)$.

Fig. 3. Growth, xylanase production and $\mathrm{pH}$ change in liquid shake cultures. Culture flasks $(250 \mathrm{ml})$ contained $50 \mathrm{ml}$ medium. Growth $(\mathrm{O})$ and xylanase production $(\square)$ in medium containing $1.5 \%(\mathrm{w} / \mathrm{v})$ xylose. $\triangle$. Xylanase production in medium containing $1.5 \%(\mathrm{w} / \mathrm{v})$ bagasse. $\mathrm{PH}$ change in medium containing bagasse.

xylan nearly doubled the enzyme yield $\left(21 \cdot 2\right.$ units $\left.\mathrm{ml}^{-1}\right)$, but addition of cellobiose, glycerol or lactose had no significant effect on the enzyme yield. However, in all cases the use of an additional carbon source resulted in more growth, as judged visually. A direct correlation between growth (mycelial crop) and enzyme productivity was, therefore, not found.

\section{Xylanase production in a fermenter}

Using the culture medium developed for the production of xylanase in shake flask cultures, the production of enzyme was studied in a fermenter. Bagasse $(1.5 \%, \mathrm{w} / \mathrm{v})$ was used as substrate for all experiments in view of its very low cost. As seen from Fig. 4, a higher rate of air-flow gave faster rate of xylanase production. With agitation at 400 r.p.m. and an air-flow of $1.21 \mathrm{~min}^{-1}$, maximal enzyme (nearly 12 units $\mathrm{ml}^{-1}$ ) was produced in $3 \mathrm{~d}$. The $\mathrm{pH}$ of the culture medium rose during the enzyme production phase and the final $\mathrm{pH}$ ranged from $7 \cdot 3$ to 8.3 . Maintaining the pH at 6.0 by the automatic addition of acid did not result in higher yield of xylanase. A noteworthy, but unexplained feature was that the growth of the fungus in the fermenter appeared, judged visually, to be better than that in shaken flask cultures. It was judged that growth reached a maximum on day 3 . During the early phase of fermentation, the bagasse remained mostly settled in the fermentation jar. At around $72 \mathrm{~h}$, the bagasse was mixed with mycelial growth and it became largely layered on the surface of the medium, resisting mixing.

\section{Xylanase iosenzymes}

To determine the number of extracellular xylanase iosenzymes produced by $M$. albomyces, the culture filtrate protein was fractionated by gel-filtration chromatography as described in Methods (Fig. 5). A small peak of activity (I) eluted immediately after the void volume of the column and it was well separated from a larger peak of xylanase (II) which eluted later. This showed that at least two xylanase isoenzymes, differing in molecular size, were produced by the 


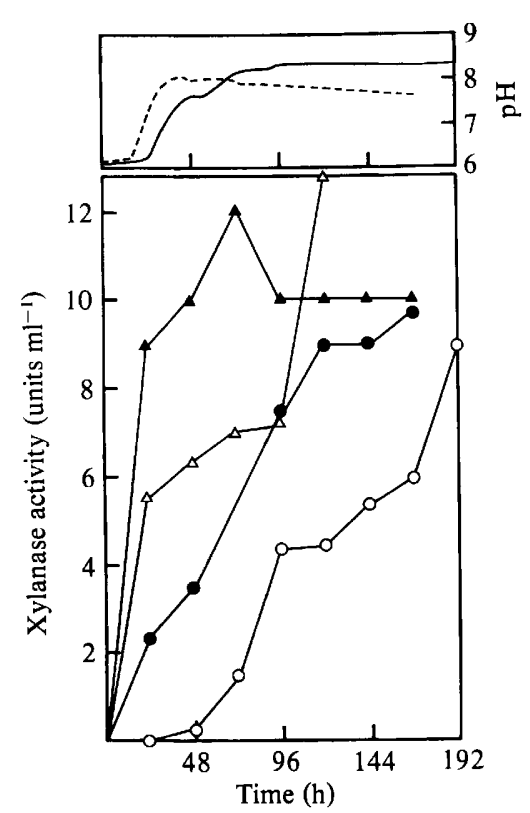

Fig. 4

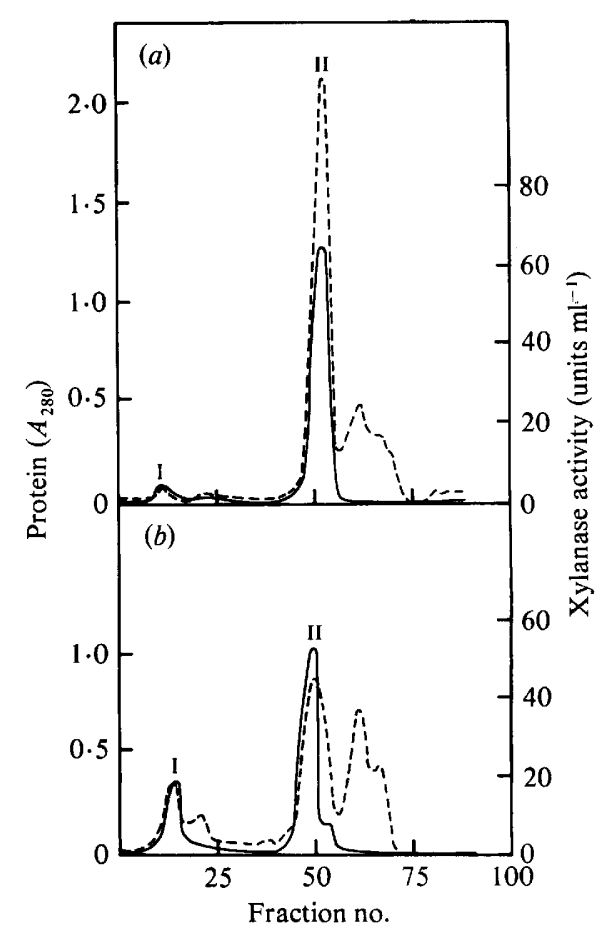

Fig. 5

Fig. 4. Xylanase production and $\mathrm{pH}$ changes in a fermenter with different rates of air-flow and agitation. $O, 0.21 \mathrm{~min}^{-1}$, 240 r.p.m.; $\bigcirc, 1.01 \mathrm{~min}^{-1}, 240$ r.p.m.; $\triangle, 1.21 \mathrm{~min}^{-1}$, 240 r.p.m.; $1.21 \mathrm{~min}^{-1}, 400$ r.p.m.; - - pH change with $\mathrm{O} ;---$, pH change with $\Delta$.

Fig. 5. Elution profile of xylanase activity in gel-filtration chromatography (Sephadex G-75) of culturefiltrate protein from $(a)$ xylose-grown, and $(b)$ bagasse-grown cultures under identical conditions. activity; --., protein. The column was eluted with water at $10 \mathrm{ml} \mathrm{h}^{-1}$, and $3 \mathrm{ml}$ fractions were collected.

fungus. Repetition of the experiment with different preparations of culture filtrate proteins gave similar results. The proportions of xylanase I and II differed considerably between xylose- and bagasse-grown cultures (Fig. 5). From the areas under the curves of enzyme activity, it was estimated that relative to culture filtrate protein, the fungus produced six times more xylanase I on bagasse than on xylose. On the other hand, the amount of xylanase II was 1-3-fold more in xylose- than in bagasse-grown cultures.

As the relative proportions of xylanase I and II in culture filtrates differed depending on the inducing substrates used (xylose or bagasse), the hemicellulolytic activity of the two culture filtrates was compared. Larchwood xylan, oat-husk xylan and hemicellulose fraction from bagasse $(5 \mathrm{mg}$ each) were incubated with $5 \mathrm{mg}$ culture filtrate protein (after DEAE-Sephadex chromatography), without shaking, in $\mathrm{pH} 6.0$ phosphate buffer $(5 \mathrm{ml})$ for $24 \mathrm{~h}$. The percentage saccharification of hemicelluloses by xylose-culture filtrate ranged from 5 to 6 , while that by bagasse-culture filtrate ranged from 6.7 to 8.2 . The results indicated that the mixture of two isoenzymes in appropriate proportions may have a synergistic action.

\section{Effect of cellulase and $\beta$-glucosidase on xylanase activity}

In several fungi xylanases are co-induced with cellulases and $\beta$-glucosidases (Dekker \& Richards, 1976; Wolter et al., 1980; Zalewska-Sobczak \& Urbanek, 1981). Moreover, in some fungi cellulases or $\beta$-glucosidase have cross-activity on xylan (Toda et al., 1971; Kanda et al., 1976; Shepherd et al., 1981; Sadana et al., 1984). Inasmuch as $M$. albomyces did not produce significant cellulase or $\beta$-glucosidase activities, it was of interest to determine if its xylanase 
Table 3. Effect of cellulase and $\beta$-glucosidase addition on xylanase activity

The concentrations $\left(\mathrm{ml}^{-1}\right)$ of the enzymes were as follows: xylanase, 0.08 unit; $\beta$-glucosidase, 1.0 unit ; cellulase (assayed on carboxymethylcellulose), 0.04 unit. The data are average values from two experiments.

\section{Enzyme present}

Xylanase
$\beta$-Glucosidase
Cellulase
Xylanase $+\beta$-glucosidase
Xylanase + cellulase
Xylanase $+\beta$-glucosidase + cellulase

\author{
Relative activity \\ on xylan
}
$1 \cdot 0$
0.06
$1 \cdot 0$
$2 \cdot 5$
$2 \cdot 8$
$3 \cdot 1$

activity would be greater if contaminated with the above enzymic activities. Therefore the activity of a partially purified preparation of xylanase of $M$. albomyces was measured in the presence of cellulase and $\beta$-glucosidase from Sporotrichum thermophile, at concentrations judged from experience to be in the normal range. Both enzymes resulted in increased production of reducing sugars in reaction mixtures containing a fixed amount of xylanase (Table 3 ).

\section{DISCUSSION}

There are very few reports of the isolation of Melanocarpus albomyces (Tansey \& Brock, 1978). Cooney \& Emerson (1964) commented that because of its thermophilic habit of growth and lack of air-borne conidia, this fungus (syn. Myriococcum albomyces) may not be widespread in occurrence. We have isolated this fungus from only two out of some 100 samples of compost or soil collected from different places in India, although the same isolation procedure was not used in all cases. We added L-sorbose and rose bengal to the isolation medium on the assumption that they would help to retard the development of the more abundant and faster-growing thermophilic species which commonly occur in soil. Both these compounds have been successfully used to reduce the colony spread of Neurospora (Tatum et al., 1949; Gochenaur, 1964). We also used L-asparagine rather than ammonium salts as the nitrogen source, based on our experience that growth of several thermophilic fungi in medium containing ammonium salts is very poor in weakly buffered media because the medium becomes too acid (Gupta \& Maheshwari, 1985). The use of special procedures may, therefore, prove rewarding in the isolation of uncommon or new species of thermophilic fungi of potential importance in biotechnology.

How good a producer of xylanase is $M$. albomyces? Quantitative comparison of xylanase production by different micro-organisms is not immediately possible for two chief reasons. First, a uniform substrate has not been adopted for the measurement of xylanase activity by various laboratories (Ghose \& Bisaria, 1984). Second, the correct measurement of the intended activity is difficult if contaminating enzymes are present. This point is illustrated by the observation of Dekker (1983) that hydrolysis of heteroxylan in $24 \mathrm{~h}$ by hemicellulolytic enzymes of Trichoderma reese $i$ was greater when exogenous $\beta$-xylosidase from Aspergillus niger was added. This effect was similar to the potentiation of cellulase activity by exogenous $\beta$-glucosidase found by Joglekar et al. (1983). Similarly, exogenous $\beta$-glucosidase from Sporotrichum thermophile enhanced the activity of xylanase from $M$. albomyces in a short-term enzyme assay (Table 3 ). This behaviour emphasizes that if xylanase production is accompanied by cellulases, $\beta$-Dglucosidases and/or $\beta$-D-xylosidases, an unreal high xylanase activity may be measured in the culture solution. However, since $M$. albomyces did not produce significant amounts of cellulase, $\beta$-glucosidase or $\beta$-xylosidase, it stands out as an exceptionally active producer of xylanase. Its extracellular xylanase activity (maximum value about 23 units $\mathrm{ml}^{-1}$ ) was some $2-4$ times higher than the values reported for some fungi which also produced some of the other enzyme activities mentioned above (Paice et al., 1978; John et al., 1979; Yoshioka et al., 1981; Dekker, 1983; 
Mishra et al., 1984). Moreover, $M$. albomyces produced high levels of xylanase in a short time when induced by sugarcane bagasse, a cheap material available in bulk. Most previous studies have used commercial xylan, presumably because this gave the best yields (lizuka \& Kawaminami, 1965; Baker et al., 1977; John et al., 1979; Biely et al., 1980; Yoshioka et al., 1981; Mishra et al., 1984).

Another noteworthy feature of $M$. albomyces is that the monomeric unit of the polysaccharide (xylose) was an effective inducer of xylanase. This is different from the situation in the yeast Cryptococcus albidus (Biely et al., 1980; Biely \& Petrakova, 1984) and in the Streptomyces sp. studied by Nakanishi et al. (1976). The rapid induction of the enzyme in washed mycelia shows that $M$. albomyces should be a suitable organism for investigations on the regulation of xylanase in mycelial fungi, providing an opportunity to study the regulation of synthesis of xylanase isoenzymes in response to different inducing substrates, particularly plant cell-wall polysaccharides and xylose-oligosaccharide fragments derived therefrom by enzymic cleavage.

This work was supported by the Department of Science and Technology, Government of India. We acknowledge the contributions and help of K. M. Bhat, P. V. Balasubramanyam and Ashok Prabhu in some experiments.

\section{REFERENCES}

von ARX, J. A. (1981). The Genera of Fungi Sporulating in Pure Culture. Vaduz: J. Cramer.

Baker, C. J., Whalen, C. H. \& Bateman, D. F. (1977). Xylanase from Trichoderma pseudokoningii: purification, characterization and effects on isolated plant cell walls. Phytopathology 67, 1250-1258.

Biely, P. \& Petrakova, E. (1984). Novel inducers of the xylan-degrading enzyme system of Cryptococcus albidus. Journal of Bacteriology 160, 408-412.

Biely, P., Kratzky, Z., VRSanka, M. \& UrmaniCOVA, D. (1980). Induction and inducers of endo-1,4$\beta$-xylanase in the yeast Cryptococcus albidus. European Journal of Biochemistry 108, 313-321.

CoOney, D. G. \& EMErson, R. (1964). Thermophilic Fungi. An Account of their Biology, Activities and Classification. San Francisco: W. H. Freeman.

DEKKER, R. F. H. (1983). Bioconversion of hemicellulose: aspects of hemicellulase production by Trichoderma reesei $\mathrm{QM} 9414$ and enzymic saccharification of hemicellulose. Biotechnology and Bioengineering 25, 1127-1146.

DekKer, R. F. H. \& Richards, G. N. (1976). Hemicellulases; their occurrence, purification, properties and mode of action. In Advances in Carbohydrate Chemistry and Biochemistry 32, 277-352.

Fall, R., Phelps, P. \& Spindler, D. (1984). Bioconversion of xylan to triglycerides by oil-rich yeasts. Applied and Environmental Microbiology 47, 1130 1134.

FliCkinger, M. C. (1980). Current biological research in conversion of cellulosic carbohydrates into liquid fuels: how far have we come? Biotechnology and Bioengineering 23, 27-48.

Ghose, T. K. \& BISARIA, V. S. (1984). Measurement of Hemicellulase Activities (Part I - Xylanases). New Delhi: Biotechnology Commission, International Union of Pure \& Applied Chemistry.

Gochenaur, S. E. (1964). A modification of the immersion tube method for isolating soil fungi. Mycologia 56, 921-923.

GupTA, S. D. \& MAHEShwaRI, R. (1985). Is organic acid required for nutrition of thermophilic fungi? Archives of Microbiologv 141, 164-169.
IrzuKa, H. \& Kawaminami, T. (1965). Studies on the xylanase from Streptomyces. Part I. Purification and some properties of xylanase from Streptomyces xylophagus nov. sp. Agricultural and Biological Chemistry 29, 520-524.

Joglekar, A. V., Karanth, N. G. \& Srinivasan, M. C. (1983). Significance of $\beta$-D-glucosidase in the measurement of exo- $\beta$-D-glucanase activity of cellulolytic fungi. Enzyme and Microbial Technology 5, 25-29.

John, M., Schmidt, B. \& Schmidt, J. (1979). Purification and some properties of five endo-1,4- $\beta$-Dxylanases and a $\beta$-D-xylosidase produced by a strain of Aspergillus niger. Canadian Journal of Biochemistry 57, $125-134$.

Kanda, T., WaKabayashi, K. \& Nisizawa, R. (1976). Xylanase activity of an endo-cellulase of carboxymethyl-cellulase type from Irpex lacteus (Polyporus tulipiferae). Journal of Biochemistry 79, 989-995.

MсСомB, R. B. \& YushoK, W. D. (1957). Colorimetric estimation of D-glucose and 2-deoxy-D-glucose with glucose oxidase. Journal of the Franklin Institute $\mathbf{2 6 5}$, 417-422.

Mishra, C., Keskar, S. \& Rao, M. (1984). Production and properties of extracellular xylanase from Neurospora crassa. Applied and Environmental Microbiology 48, 224-228.

Nakanishi, K., Yasui, T. \& Kobayashi, T. (1976). Inducers of xylanase production by Streptomyces sp. Journal of Fermentation Technology 54, 801-807.

Paice, M. G., Jurasek, L., Carpenter, M. R. \& Smille, L. B. (1978). Production, characterization and partial amino acid sequence of xylanase A from Schizophyllum commune. Applied and Environmental Microbiology 36, 802 -808.

Paturau, J. M. (1982). By-products of the Cane Sugar Industry: an Introduction to their Industrial Utilization, Series 3, p. 33. Amsterdam: Elsevier Scientific.

Roos, W. \& LuckNer, M. (1984). Relationship between proton extrusion and fluxes of ammonium ions and organic acids in Penicillium cyclopium. Journal of General Microbiology 130 , 1007-1014. 
Sadana, J. C.. Lachke, A. H. \& Patil, R. V. (1984). Endo-(1,4)- $\beta$-D-glucanases from Sclerotium rolfsii. Purification, substrate specificity and mode of action. Carbohydrate Research 133, 297-312.

Shepherd, M. G., Tong, C. C. \& Cole, A. L. (1981). Substrate specificity and mode of action of the cellulases from the thermophilic fungus Thermoascus aurantiacus. Biochemical Journal 193, 67-74.

SomoGyi, M. (1952). Notes on sugar determination. Journal of Biological Chemistry 195, 19-23.

TANSEY, M. R.\& BROCK, T. D. (1978). Microbial life at high temperatures. Ecological aspects. In Microbial Life in Extreme Entironments, chapter 5. Edited by D. J. Kushner. London: Academic Press.

Tatum, E. L., Barratt, R. W. \& Cutter, V. M., JR (1949). Chemical induction of colonial paramorphs in Neurospora and Sincephalastrum. Science 109. $509-511$.
Toda, S., Slzuki, H. \& Nisizawa, K. (1971). Enzymatic properties and the substrate specificities of Trichoderma cellulases with special reference to their activity towards xylan. Hakko Kogaku Zasshi 49, 499-521

Wolter, K., Highley, T. \& Evans, F. (1980). A unique polysaccharide and glycoside degrading enzyme complex from the wood decay fungus, Poria placenta. Biochemical and Biophysical Research Communications 97, 1499-1504.

Yoshioka, H., Chavanich, S., Nilubol, N. \& Hayashida, S. (1981). Production and characterization of thermostable xylanase from Talaromyces b! ssochlamydoides YH-50. Agricultural and Biological Chemistry 45, 2425-2432.

Zalewska-SobcZak, J. \& URbanek, H. (1981). Cellulose and xylan-degrading enzymes of Fusarium arenaceum. Archices of Microbiology 129, 247-250. 